\title{
Medico-Legal Implications of Assessing Unreliability in Civil Compensation Cases: A Case Study Reflecting Potential Unreliability
}

\author{
Koch $\mathrm{HCH}^{1 *}$, Court $\mathrm{K}^{2}$, and Bates $\mathrm{S}^{3}$ \\ ${ }^{1}$ Clinical Psychologist, Cheltenham and Gloucester Nuffield Hospital, and Visiting Professor, School of Law, Stockholm University, \\ Sweden \\ ${ }^{2}$ Clinical Psychologist, Cheltenham and Plymouth, UK \\ ${ }^{3}$ Clinical Psychologist, Cheltenham and Thatcham, UK
}

${ }^{*}$ Corresponding author: Koch HCH, Clinical Psychologist, Cheltenham and Gloucester Nuffield Hospital, Visiting Professor to Stockholm University, Sweden, Tel: 0044-1242-263715, Fax: 01242 528299, E-mail: hugh@hughkochassociates.co.uk

Citation: Koch HCH (2017) Medico-Legal Implications of Assessing Unreliability in Civil Compensation Cases: A Case Study Reflecting Potential Unreliability. SAJ Case Reports 4: 106

Article history: Received: 07 February 2017, Accepted: 28 February 2017, Published: 02 March 2017

\begin{abstract}
The expert witness assessing claimant self-report behaviour in the interview needs to be able to identify characteristics reflecting reliability and/or unreliability. This case study uses interview data to illustrate key aspects of veracity and its implications for therapeutic jurisprudence. Conclusions about using a checklist for unreliability are made.
\end{abstract}

Keywords: Reliability; Truthfulness; Non-verbal Behaviour; Work Accident; Logicality

\section{Introduction}

When collecting evidence in a civil claim for personal injury such as a work accident, the expert witness (of any clinical/medical speciality) must be mindful of the reliability of data and truthfulness of the claimant.

The importance of maintaining a 'moral compass' between various conflicts or inconsistencies of data is a complex task undertaken by lawyers and experts, working together with independence, impartiality and logicality [1] and reflects an increasingly 'therapeutic' or 'continuous improvement' approach to contemporary 21st century litigation [2].

\section{Legal Issues in Reliability Assessment}

From a legal perspective, evidential reliability is based on the quality and extent of the available data, inferences made, precision and validity of test results-however, the central data is that of the claimant's self-report, obtained from a face-to-face interview. From this, key medico-legal questions of causation, attribution, diagnosis, duration and prognosis can be answered. Recent Legal Mind cases and commentaries [3-6] have illustrated this. Within the interview assessing psychological injury, there are many areas of potential unreliability $[7,8]$ both clinical and medico-legal. Many of these are explored via the interview and a series of verbal, non-verbal and procedural indicators aid the expert in his/her assessment of reliability [9].

\section{The Case Study Model for Deception Detection}

The key to assessing malingering and deception in forensic, judicial and clinical contents is to ascertain the extent to which communications are congruent [10]. The expert uses a semi-instructed interview to 'listen' for descriptions of symptoms which may appear unsound or unreliable [11]. Examples of possible unreliable communications such as non-verbal behaviour (e.g. speech hesitation), verbal behaviour (e.g. level of detail, superficiality) and general characteristics (e.g. inappropriate language, suggestibility, inconsistency) have been illustrated with reference to actual interview data [9] These must, however, be considered in the context of interviewing to detect deception still being a very difficult area of inquiry with general detection rates being problematic. An anonymised case study in shown below.

\section{Case Study: Highlighting Unreliability}

Mrs. Smith (43) lives in London and works as a hospital cleaner. Whilst at work she slipped on a wet hospital floor, injured her back 
and her left leg and hit her head. She was off work for six months. She reported that she became depressed while off work and also developed social anxiety about being out of home and walking on non-dry surfaces.

The following summary (Figure 1) of statements made in her interview with a clinical psychologist/expert witness is shown below with relevant unreliability characteristics of potential unreliability alongside to highlight the expert's reaction to what he was being told.

Figure 1: Example of unreliable non-verbal behaviour

\begin{tabular}{|c|c|}
\hline \multirow{2}{*}{ Interview Statement } & Unreliability Characteristic \\
\hline & Vocal Characteristics \\
\hline $\begin{array}{l}\text { Q1. Where do you have pain? } \\
\text { A1. Er, umm, all over - most of the time, especially when I bend } \\
\text { down. }\end{array}$ & $\begin{array}{l}\text { 1. Speech hesitations: use of words 'ah', 'um', 'er' and } \\
\text { so on. }\end{array}$ \\
\hline $\begin{array}{l}\text { Q19. Did you go to see your GP straight away? } \\
\text { A19. No, the next day, or maybe three days later - I can't be sure. }\end{array}$ & $\begin{array}{l}\text { 2. Latency period: period of silence between question } \\
\text { and answer. } \\
\text { 3. Speech errors: word and/or sentence repetition, } \\
\text { sentence change, sentence incompletions, slips of the } \\
\text { tongue. }\end{array}$ \\
\hline Q7. Have you ever had any psychological care or advice before this & Facial Characteristics \\
\hline $\begin{array}{l}\text { accident at work? } \\
\text { A7. (Look away before answering, then answer without looking at } \\
\text { X). Five second pause. No I don't think so, it's hard to answer. }\end{array}$ & 4. Gaze: avoiding the face of the conversation partner. \\
\hline $\begin{array}{l}\text { Q9. Excuse me asking, but have you ever had any problems with the } \\
\text { police? } \\
\text { A9. (Shifting in chair, move legs). No, not really - nothing serious. } \\
\text { (Blinking three times in rapid succession). }\end{array}$ & 5. Blinking: Blinking of the eyes. \\
\hline Q11. If I had met you just before this accident at work, how were & Movements \\
\hline $\begin{array}{l}\text { you feeling? } \\
\text { A11. (Scratching her head a lot; pausing) just after the accident? } \\
\text { Q12. No, just before. } \\
\text { A12. I was ok. (Pause). I had been a bit nervous and down at work } \\
\text { and my GP had given me some antidepressant tablets - I think it } \\
\text { was then, or it might have been a couple of months before - I can't } \\
\text { remember. }\end{array}$ & 6. Self-manipulations: scratching the head. \\
\hline $\begin{array}{l}\text { Q7. Have you ever had any psychological care or advice before this } \\
\text { accident at work? } \\
\text { A7. (Look away before answering, then answer without looking at } \\
\text { X). Five second pause. No I don't think so, it's hard to answer. }\end{array}$ & $\begin{array}{l}\text { 7. Shifting position: movements made to change the } \\
\text { sitting position (usually accompanied by trunk and } \\
\text { foot/leg movements). Frequent non-verbal indications } \\
\text { of discomfort. }\end{array}$ \\
\hline
\end{tabular}

In Figure 2 below examples of statements are given which can indicate general characteristics of reliability and truthfulness which can be balanced against other indications of un-reliability. The expert interviewer must be mindful not to place too much emphasis on any one facet of behaviour.

Figure 2: Interview Statements

\begin{tabular}{|c|c|}
\hline General Characteristics & $\begin{array}{c}\text { General Characteristics of Reliability and } \\
\text { Truthfulness }\end{array}$ \\
\hline $\begin{array}{l}\text { Q16: Was the ward busy that day? } \\
\text { A16: I remember it was. We had had an inspection and everyone } \\
\text { was trying to keep up the ward clean and tidy - the ward sister had } \\
\text { asked for the floor to be washed a second time. }\end{array}$ & $\begin{array}{l}\text { 1. Logical structure } \\
\text { 2.Unstructured production } \\
\text { 3. Quantity of details }\end{array}$ \\
\hline \multicolumn{2}{|l|}{ Specific Content } \\
\hline $\begin{array}{l}\text { Q14: I understand you slipped on a wet hospital floor? } \\
\text { A14: Something like that, there was lots of rubbish on the ward. I } \\
\text { remember the floors had been washed that morning. }\end{array}$ & $\begin{array}{l}\text { 4. Unexpected complications during the incident } \\
\text { 5. Unusual details } \\
\text { 6. Superfluous details }\end{array}$ \\
\hline $\begin{array}{c}\text { Q17: Did you lose consciousness when you fell over? } \\
\text { A17: I think so, I was in shock - I was worried I was seriously } \\
\text { injured. }\end{array}$ & 7. Accounts of subjective mental state \\
\hline $\begin{array}{l}\text { Q24: How long did you have off work? } \\
\text { A24: About six months. I returned to work on my birthday, six } \\
\text { months later. I remember because several staff gave me cards. }\end{array}$ & 8. Contextual embedding \\
\hline $\begin{array}{l}\text { Q26: Dr Jones' medical report says you were off work for four } \\
\text { months. } \\
\text { A26: I was, but when I went back, after } 2 \text { hours I couldn't cope with } \\
\text { back pain and dizziness and had another } 2 \text { months off. }\end{array}$ & 10. Reproduction of conversation \\
\hline
\end{tabular}


Having considered the actual verbal and non-verbal behaviour of the claimant in the face-to-face interview, the expert then assesses a number of psychological characteristics which can reveal underlying unreliability (Figure 3).

Figure 3: Psychological Characteristics of Unreliability.

\begin{tabular}{|c|c|}
\hline Interview Statements & Psychological Characteristics of Unreliability \\
\hline $\begin{array}{l}\text { Q18. When it was happening did you think you were going to be severely injured? } \\
\text { A18. Oh yes, after I got up, a nurse said I was lucky not to be paralysed. I think I } \\
\text { had stress and depression. (No emotion shown). }\end{array}$ & $\begin{array}{l}\text { 1. Inappropriateness of language and knowledge } \\
\text { 2. Inappropriateness of affect }\end{array}$ \\
\hline $\begin{array}{l}\text { Q20. Did you see your GP again? Did anyone suggest you go? } \\
\text { A20. Sorry, I'm not sure. Yes about two weeks later I think - not sure. Yes, my } \\
\text { brother suggested this would be a good idea. }\end{array}$ & 3. Questionable motives to report \\
\hline $\begin{array}{l}\text { Q21. Did your GP suggest any treatment? } \\
\text { A21. Oh yes, we talked about it - I got given some tablets. I wasn't there long, } \\
\text { he's always very busy. I do remember him saying he had a fall in his surgery. My } \\
\text { brother who is a psychologist, suggested I have counselling. }\end{array}$ & $\begin{array}{l}\text { 4. Questionable context of the original disclosure or } \\
\text { report }\end{array}$ \\
\hline $\begin{array}{l}\text { Q22. Over the next few weeks, did you have problems sleeping? } \\
\text { A22. Yes, I had nightmares every night, always about this awful accident and } \\
\text { sleeping. I also had flashbacks a lot, remembering what happened very vividly. My } \\
\text { partner thought I had PTSD. I still have nightmares almost every night. }\end{array}$ & $\begin{array}{l}\text { 5. Pressures to report falsely (e.g. avoid detection; } \\
\text { obtain compensation) } \\
\text { 6. Inconsistency with the laws of nature }\end{array}$ \\
\hline $\begin{array}{l}\text { Q26. Dr Jones' medical report says you said you were off work for four months? } \\
\text { Q26. I was, but when I went back, after two hours I couldn't cope with my back } \\
\text { and had another two months off. }\end{array}$ & 7. Inconsistency with other statements. \\
\hline $\begin{array}{l}\text { Q30. How is walking confidence now, twelve months on? } \\
\text { A30. A little better, but I notice in crowded situations or wet surfaces I am still } \\
\text { nervous. }\end{array}$ & 8. Susceptibility to suggestion \\
\hline $\begin{array}{l}\text { Q33. Reading your GP notes I see you had several prescriptions for } \\
\text { antidepressants and sedatives in 2010, 2012, } 2013 \text { and 2015? } \\
\text { A33. I'd forgotten about this. } \\
\text { Q34. Post-accident, there is no reference to the work accident in GP attendance } \\
\text { and no extra medication prescribed, just previous sedatives. } \\
\text { A34. It is difficult to remember all this. }\end{array}$ & 9. Inconsistency with other evidence. \\
\hline
\end{tabular}

\section{Outcome and Discussion}

The expert witness has the unenviable task of collating not only basic self-report and medical record information but also the large number of characteristics of potential reliability or unreliability [12]. As yet, there is no systematic or scientific way of doing this. However the use of the several deception detection variables illustrated in the case study statements in Figures. 1-3 are an important basis on which to identify, collect and debate levels of reliability and truthfulness in claimants. Further work is underway to develop a scientific way to more formally operationalise this data on three overlapping dimensions of reliability, defensiveness and malingering - this case study method is an invaluable tool to support and progress this process and hence be able to advise the court on veracity and evidential certainty. Recent work [13] on developing a tool to increase the validity of judgements of credibility in medico-legal settings is being investigated and will be the subject of further research and publications [14]. This analysis is important for lawyers and experts, qualified and in training to be aware of. Alongside this type of analysis, credibility assessment is also aided by serial interviews, interviews with 'significant others', understanding effects of poor memory on recall and being aware of the differential effects of anxiety on behaviour and responding. The final question which the proverbial 'Judge' will ask ("Dr. Expert, putting all this information and inference together, how reliable or truthful is Mr. X?") is still an extremely difficult one to answer logically and reliably. However, this work on identifying and attempting to interpret in a balanced and logical way the extent of unreliability or untruthfulness is crucial in forensic, judicial and clinical contexts. This should be a subject taught at undergraduate and postgraduate levels of both psychology and law courses and also a key topic considered as part of CPD for qualified and experienced experts in the field.

\section{References}

1. Koch HCH (2016) Keeping our Moral Compass. Modern Law, 25.

2. Diesen C, Koch HCH (2016) Contemporary 21st Century Therapeutic Jurisprudence in Civil Cases: Building Bridges Between Law \& Psychology. Ethics, Med Pub Health. 2: 13-26.

3. Koch HCH, Newns K (2016) Psychological Disorder: Sudden shock or series of distressing events. Legal Mind Case and Commentary: PIBULJ, April.

4. Koch HCH, Hetherton J (2016) Who knows best? The Judge or the Expert? Legal Mind Case and Commentary: No. 10. PIBULJ, September.

5. Koch HCH, Robertson C (2016) Material Contribution: Little or Large? Legal Mind Case and Commentary No. 11 PIBULJ, November.

6. Koch HCH, Addy K (2016) Material contribution and the 'but for' test. Legal Mind Case and Commentary: No. 2 PIBULJ, May.

7. Koch HCH (2016) Medico-legal Case Commentary: Interface Between Clinical Opinion and Legal Case Reporting in Personal Injury Litigation. Mathews Open Acs J 005.

8. Koch HCH, Newns K, Boyd T, Peters J (2016) Assessing Malingering and Deception in Forensic, Judicial \& Clinical Contexts: Are Various Communications 'Congruent'? Expert Witness J. 
9. Vrij A (2008) Detecting Lies and Deceit: Pitfalls and Opportunities. 2nd Edition, Wiley Chichester.

10. Koch HCH (2016) Legal Mind: Contemporary Issues in Psychological Injury and Law. Expert Witness Publications Articles Library.

11. Koch HCH, Elson P (2016) Areas of Medico-legal Unreliability in Personal Injury Cases. MJ Case 2: 0024.

12. Oxburgh G, Mykleburst T, Grant T, Milne R (2015) Communication in Investigative and Legal Contexts. Wiley: 402.

13. Akehurst L, Easton S, Fuller E, Drane G, et al. (2017) An Evaluation of a New Tool to Aid Judgement of Credibility in the Medico-legal Setting. Legal Crim Psy 22: $22-46$.

14. Akehurst L, Koch HCH, Easton S (2017) Judging credibility in road traffic accidents; A Case Study. (In Preparation) 